\title{
Revisão Sistemática da Utilização de Far-UVC e Ozônio no Combate à Covid-19 e demais Patógenos
}

\author{
Guilherme V. L. Silva, Gustavo M. Camargo, José A. S. Neto, \\ Igor D. Borges, Cláudio F. Oliveira \& Rosemberg R. F. Nunes
}

Frente ao desafio de explorar novos meios de uma mitigação eficiente e acessível para inativação de patógenos e limitar sua transmissão em ambientes ocupados por pessoas, surgiu a iniciativa desta investigação que teve como objetivo primário realizar uma revisão sistemática, buscando na literatura o estado da arte em relação à utilização de radiação UVC e Ozônio como agentes germicidas no combate de vírus e bactérias.Foram pesquisados nos bancos de dados trabalhos que continham as strings "UVC" AND "wave" AND "ultraviolet" AND "radiation" AND "light" AND" intensity" e também "ozone" AND "air" AND "disinfection" AND "virus" AND "bacteria" AND "environment" AND "decontamination" AND "air decontamination". A busca foi feita nas bases de dados ScienceDirect, Web of Science, pubMED, SciELO, Google Scholar e World Wide Science. Foram encontrados 189 artigos relacionados à utilização de UVC como agente germicida e 16 artigos acerca da utilização do ozônio, totalizando assim 205 artigos. Destes somente 44 foram selecionados para a revisão, os outros trabalhos não foram selecionados, pois não se enquadraram no critério de seleção, seja por possuir uma aplicação diferente da proposta pelo grupo, exemplo artigos que relacionavam a utilização da radiação UVC no tratamento de águas residuais ou por a data de publicação não se enquadrar no período de 2016 a 2020, nenhum artigo utilizando ambos os agentes germicidas ozônio e UVC foi encontrado. Entretanto, entres os artigos selecionados, foram relatadas informações importantes e promissoras para dar firmamento e veracidade às premissas adotadas pelos pesquisadores.

Palavras-chave: SARS-COV2; esterilização; pandemia; corona; duo cannon.

Faced with the challenge of exploring new means of efficient and accessible mitigation to inactivate pathogens and limit their transmission in environments occupied by people, the initiative for this investigation arose, which had as its primary objective to carry out a systematic review, searching the state of the art in relation to the use of UVC and ozone radiation as germicidal agents in the fight against viruses and bacteria. Researches were carried out in the databases that contained the strings "UVC" AND "wave" AND "ultraviolet" AND "radiation" AND "light" AND "intensity "and also" ozone "AND" air "AND" disinfection "AND" virus "AND" bacteria "AND" environment "AND" decontamination "AND" air decontamination ". The search was carried out in the ScienceDirect, Web of Science, pubMED, SciELO, Google Scholar and World Wide Science databases. 189 articles were found related to the use of UVC as a germicidal agent and 16 articles about the use of ozone, thus totaling 205 articles. Of these, only 44 were selected for the review, the other studies were not selected, as they did not fit the selection criteria, either because they have an application different from that proposed by the group, for example articles that related the use of UVC radiation in the treatment of wastewater. or because the publication date does not fall within the period from 2016 to 2020 , no article was found using both the ozone and UVC germicidal agents. However, among the selected articles, important and promising information was reported to give firmament and veracity to the assumptions adopted by the researchers.

Keywords: SARS-COV2; sterilization; pandemic; corona; duo cannon. 


\section{Introdução}

Segundo um estudo publicado no The Lancet ${ }^{1}$, na data de 01/12/2019 foi identificado o primeiro paciente com um surto de pneumonia viral que atingiria a cidade de 11 milhões de habitantes Wuhan, na China. Na data de 20 de dezembro, 19 dias depois do primeiro caso, segundo o relatório do governo chinês, publicado no South China Morning Post ${ }^{2}$, o número de casos confirmados até este dia chegou a 60. Até esta data não havia evidências de transmissão de humano para humano do novo coronavírus. No dia 25 de dezembro, o dr. Lu Xiaohong, diretor do departamento de gastroenterologia do hospital número 5 de Wuhan, afirmou que havia suspeita de que membros da equipe médica de dois hospitais da cidade contraíram a pneumonia viral. Somente 24 dias depois, foi emitido um relatório confirmando a transmissão de humano para humano do novo coronavírus. Três meses depois, a organização mundial da saúde OMS decreta uma pandemia. Até o momento da elaboração desta revisão os números de casos em 23/11/2020 era de 58.425.681 casos confirmados e 1.385.218 mortes contabilizados pela OMS dados esses que podem ser acessados no dashboard Figura 1 disponível no site da $\mathrm{OMS}^{3}$.
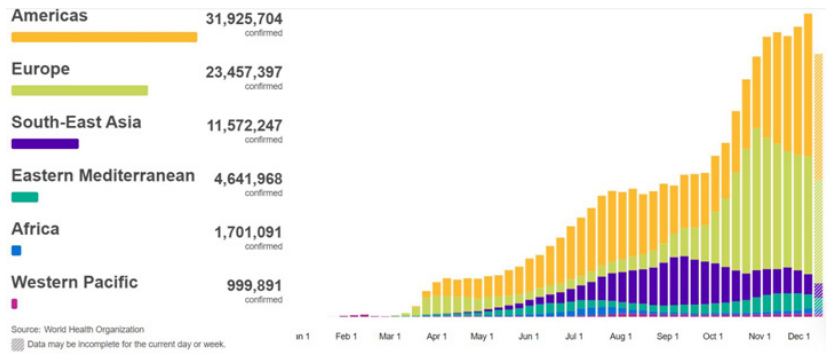

Figura 1: Evolução do Covid-19 no mundo. Fonte: Organização mundial da saúde ${ }^{3}$

Mesmo havendo pesquisas promissoras, atualmente, não há medicamentos antivirais licenciados pela Food andDrugAdministration (FDA) dos Estados Unidos, pela European Medicines Agency (EMA), pela Spanish Agencyof Medicines and Medical Devices (AEMPS) ou pela Italian
Drug Agency para tratar pacientes com COVID-19. Nenhum medicamento antiviral para tratar pacientes com COVID-19 foi licenciado em qualquer país do mundo até agora. Assim como a pandemia de COVID-19 veio após a crise de sars de março de 2003, a comunidade científica sabe que novas pandemias virão após a COVID-19. Sendo assim, é extremamente importante explorar tecnologias de mitigação prática para inativação dos agentes patogênicos transportados pelo ar em locais públicos, limitando, assim, a transmissão aérea ${ }^{4-6}$.

Um dos processos mais utilizados para a prevenção de transmissão de patógenos transportados pelo ar é a ventilação forçada, que elimina prontamente os organismos infecciosos pelo aumento na taxa de troca de ar, essa abordagem não é completamente eficaz. Atualmente, os filtros de ar com alta eficiência na separação de partículas (HEPA) são as alternativas que possuem maior eficiência, entretanto é uma premissa com alto custo de funcionamento ${ }^{7,8}$. As alternativas a serem exploradas no decorrer deste trabalho serão a utilização de espectro de luz UVC e o gás oxidante ozônio.

\section{OZÔNIO}

$\mathrm{O}$ ozônio $\left(\mathrm{O}_{3}\right)$ é um gás instável que compreende três átomos de oxigênio produzidos naturalmente na estratosfera pela ação fotoquímica dos raios ultravioleta sobre as moléculas de oxigênio ${ }^{8,9}$. Esses raios são

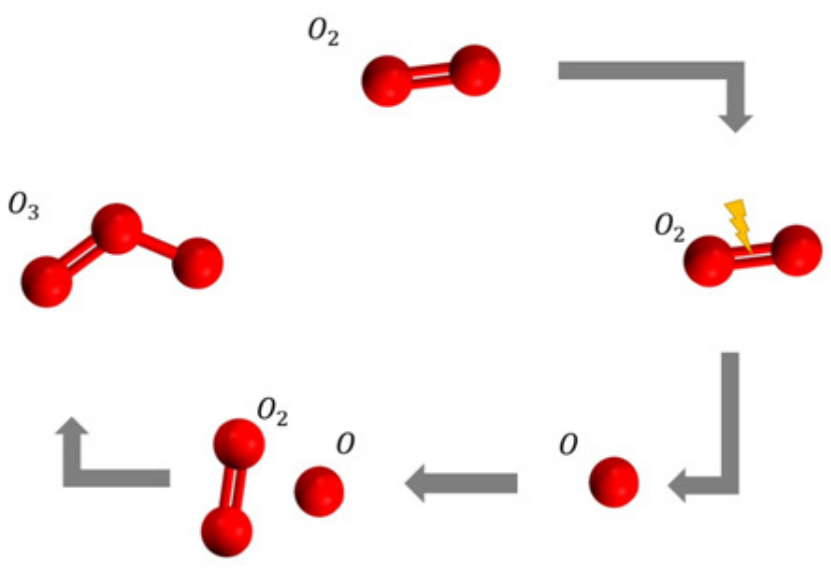

Figura 2: Processo de síntese de ozônio. Fonte: Autores 
suficientemente intensos para separar os dois átomos que compõem a molécula de $(\mathrm{O} 2)$ produzindo assim o oxigênio atômico Figura 2. A produção de ozônio é realizada numa etapa imediatamente posterior, resultando da associação de um átomo de oxigênio e uma molécula de $(\mathrm{O} 2)$ na presença de um catalisador ${ }^{8}$.

É um gás oxidante poderoso e com ação microbicida eficaz, isto é, elimina bactérias, fungos e vírus em superfícies e líquidos ${ }^{10,11}$. A utilização do ozônio em tratamentos de águas residuais está documentada e demonstra aplicações na maioria das cidades modernas $^{8,12}$. Embora os estudos acerca da utilização do ozônio para esterilizar superfícies ainda sejam limitados, resultados experimentais já provaram que a utilização do ozônio é uma alternativa eficaz para desinfetar ar e superfícies ${ }^{13}$. De acordo com o artigo "Bactericidal Effects of High Airbone Ozone Concentrations In Escherichia coli na Staphylococcus aureus" escrito pelos pesquisadores W.J kowalski, W.P Bashnfleth e T.S. Whittam, foram investigados os efeitos bactericidas de altas concentradores de ozônio nas bactérias bacilar Escherichia coli e na bactéria Staphylococcus aureus frequentemente encontrada na pele e fossas nasais de pessoas. Essa pesquisa concluiu que mais de $99,99 \%$ da taxa de mortalidade foi alcançada para ambas as espécies após a exposição ao Ozônio $^{12}$. Além da capacidade oxidante do gás ozônio, as suas propriedades também colaboram para ser um desinfetante aéreo ideal, em contraste com a radiação ultravioleta, troca de ar e filtros HEPA, o ozônio é um gás que pode facilmente penetrar em todos os cantos de um ambiente fechado, sendo assim pode esterilizar de forma eficaz ${ }^{8}$. Por conta da instabilidade do gás ozônio, ele é rapidamente convertido em oxigênio, não deixando nenhum resíduo prejudicial após a desinfecção ${ }^{8}$.

Os átomos ou radicais livres do oxigênio são altamente reativos e oxidantes, oxidando quase tudo, incluindo vírus, bactérias, compostos orgânicos e não orgânicos em contato, tornando o ozônio um desinfetante e oxidante poderoso ${ }^{11}$. O ozônio é um oxidante muito mais forte do que outros desinfetantes comumente utilizados, como o cloro e o hipoclorito ${ }^{8}$. O uso de cloro ou hipoclorito em muitos países diminuiu significativamente devido à possibilidade de formação de subprodutos carcinogênicos, como trihalometanos (THM) durante processo de desinfecção ${ }^{8}$. Em contraste, a desinfecção com ozônio não produz resíduos prejudiciais e todo o ozônio residual será convertido de volta em oxigênio em um curto espaço de tempo ${ }^{8}$. O ozônio é, portanto, considerado um desinfetante ambientalmente correto $^{8}$. Dada sua força e eficácia superiores como oxidante e biocida, o ozônio se torna uma das tecnologias de tratamento de água dominantes na Europa e na América. Mas sua aplicação na desinfecção do ar não é tão popular quanto a água devido à preocupação com a toxicidade do ozônio ${ }^{8,14}$. $\mathrm{O}$ ozônio com concentração superior a $1 \mathrm{ppm}$ (parte por milhão, $1 \mathrm{ppm}$ é igual a $1 \mathrm{~g} / \mathrm{m}^{3}$ grama por metro cúbico) causa efeitos adversos à saúde humana e o uso de ozônio para desinfecção do ar geralmente não é recomendado se houver pessoas por perto ${ }^{8}$. Portanto, a desinfecção do ar com ozônio deve ser restrita apenas a salas desocupadas.

\section{UVC}

O espectro de luz UVC nada mais é que uma onda eletromagnética, na qual transportam uma quantidade de energia mínima, em proporção inversa ao seu comprimento de onda ${ }^{15}$. Sendo assim, quanto menor for o comprimento de onda, mais energética será a radiação transportada por ela. A radiação ultravioleta UV representa parte do espectro eletromagnético com o comprimento de onda menor que o da luz violeta, ou seja, uma faixa imediatamente mais energética do que a luz visível $^{16-18}$. Devido à quantidade de energia transportada nas ondas UV, elas estão no limite denominado Região ionizante do espectro eletromagnético, isso indica que as ondas possuem condições de formar íons, o que significa ter condições de causar danos a moléculas de DNA $^{19,20}$. 


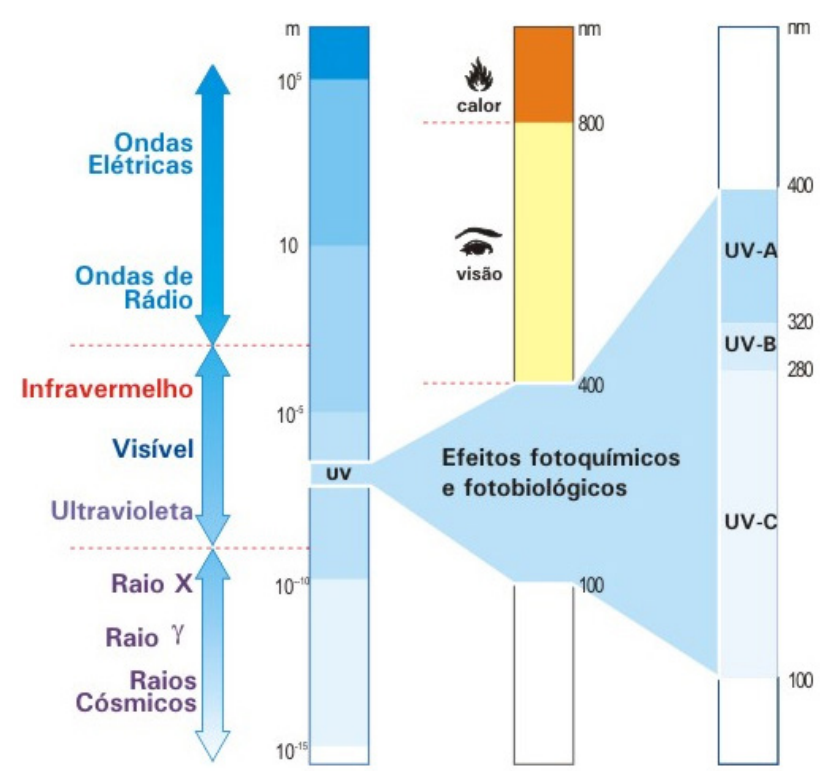

Figura 3: Divisões das energias eletromagnéticas. Fonte: Akari lâmpadas especiais e leds IR UV ${ }^{21}$

Como pode ser visto na Figura 3, o espectro ultravioleta se situa entre a luz visível e os raios $\mathrm{X}$. Pode se verificar que ela se divide em três regiões: UV-A, UV-B e UV-C. o espectro UVA (radiação de ondas longas) possuindo comprimento de $315 \mathrm{~nm}$ (nanômetro) até 400nm, UVB (radiação de ondas médias) 280nm até 315 e UVC(radiação de ondas curtas) de $100 \mathrm{~nm}$ a $280 \mathrm{~nm}^{22-27}$. A ação germicida da radiação UV se dá na região UV-C e no comprimento de onda de $208 \mathrm{~nm}$ a $254 \mathrm{~nm}$, fora dessa região, a ação germicida é reduzida ${ }^{18,22,24,28,29}$.

Esse espectro de luz possui duas fontes: natural ou artificial, sendo a fonte natural o Sol que gera os espectros UV-A, UV-B e UV-C e como fonte artificial, as lâmpadas. As lâmpadas com comprimento de onda longos e médios são utilizadas para bronzeamento artificial e luz negra, muito comum em decoração de ambientes. Já as lâmpadas de ondas curtas UV-C são destacadas por promoverem a ação germicida ${ }^{17,22,23,30,34}$.

Quando a radiação UV interage com uma entidade biológica, seja uma bactéria, uma célula da nossa pele ou até um vírus, por ser ionizante, ela tem condições de causar danos ao material genético ${ }^{19,20}$. Dependendo dos fatores de exposição que foi comentado, esse processo pode matar a célula, a bactéria ou desativar um vírus ${ }^{22,35,36}$.

Como pode ser visto nas Figuras 4 e 5, ao adentrar ao interior dos microrganismos, à radiação UVC provoca um dano fotoquímico instantâneo no $\mathrm{DNA}^{37}$ (ácido nucleico - material genético essencial para todos os seres vivos) essa alteração no DNA causa efeito esterilizante independente do ambiente que esses organismos se encontram seja água ou $\mathrm{ar}^{22,36,38,39}$.

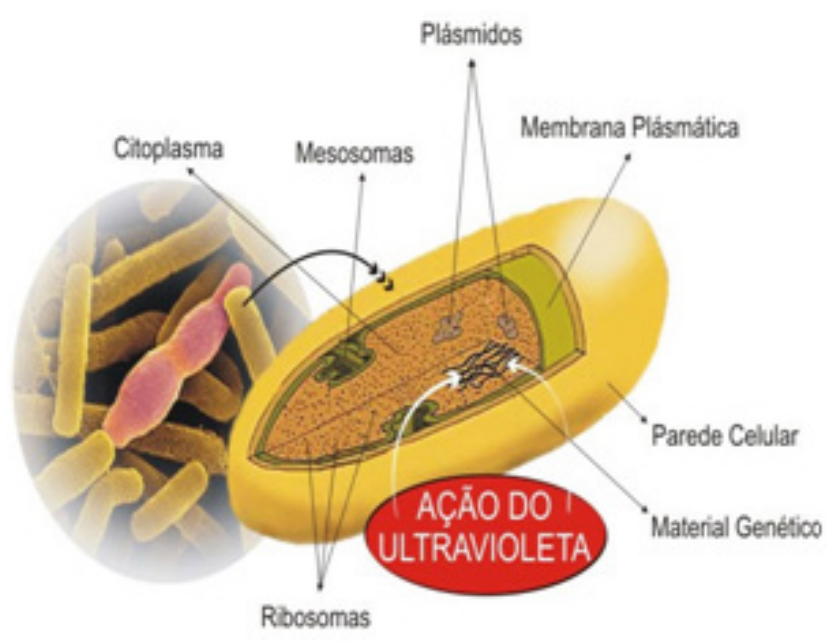

Figura 4: Local de ação do espectro UVC nas células de um vírus. Fonte: Fabricante de lâmpadas AKARI ${ }^{21}$
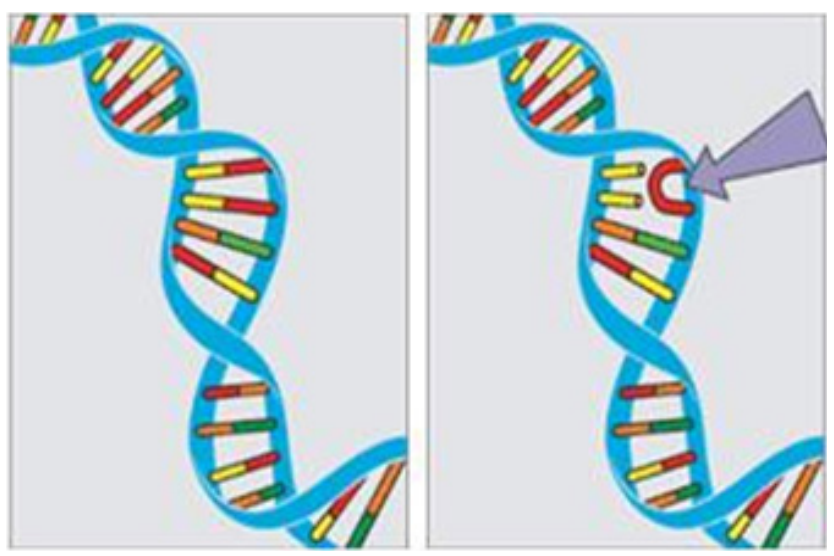

Figura 5: Ação do espectro UVC em uma estrutura de DNA. Fonte: Fabricante de lâmpadas AKARI ${ }^{21}$ 
Apesar do uso das lâmpadas UVC de $254 \mathrm{~nm}$ para esterilização não deixar nenhum resíduo, é de conhecimento do meio acadêmico que esse comprimento de onda é prejudicial à pele e aos olhos, pois a exposição a radiações ionizantes tem poderes cancerígenos e catarogênicos ${ }^{40-42}$. Os efeitos mais críticos em humanos e cobaias animais (geralmente ratos) é o câncer cutâneo causado por genotoxicidade $^{40}$.

Em tese, o Far- UVC é a luz ultravioleta que abrange o comprimento de onda de 207 a $222 \mathrm{~nm}$, o qual mostrou-se tão eficiente quanto a luz ultravioleta germicida convencional em inativar microorganismos, mas não tem os problemas de saúde humana associados à luz ultravioleta germicida convencional. A explicação biofísica é que, devido ao seu curto intervalo em material biológico, a luz UVC (207 a $222 \mathrm{~nm}$ ) não consegue penetrar no estrato córneo humano (camada externa de células mortas, espessura de $5-20$ $\mu \mathrm{m})$ nem mesmo no citoplasma das células de indivíduos humanos ${ }^{22,40,41,43}$. Resumindo, a razão é que o Far-UVC tem um alcance em materiais biológicos de apenas alguns micrômetros e, portanto, não pode alcançar células humanas vivas na pele ou nos olhos ${ }^{22,38,44}$.

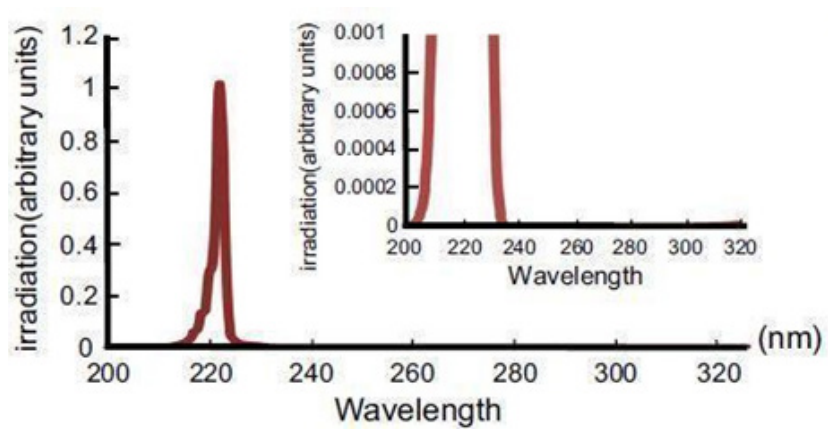

Figura 6: Espectro medido de um irradiador (Lâmpada UVC $222 \mathrm{~nm}$ ). Região UVC: a quantidade de UV de $230-235 \mathrm{~nm}$ é $0,26 \%$ da quantidade de UV de $200-230 \mathrm{~nm}$, e a quantidade de UV de 235 - 280 é $0,13 \%$ da quantidade de UV de 200 - 230. Região UVB, a quantidade de UV de 280 $-320 \mathrm{~nm}$ é $0,04 \%$ da quantidade de UV de $200-230 \mathrm{~nm}^{44}$. Fonte: Longterm Effects of $222-n m$ ultraviolet radiation C Sterilizing Lamps on Mice Susceptible to Ultraviolet Radiation ${ }^{44}$.
Mas como partículas nocivas são extremamente pequenas, o Far-UVC ainda pode penetrá-los e destruí$\operatorname{los}^{17,22}$. Até agora, a luz UVC tem quase as mesmas propriedades germicidas altamente eficazes da luz UV, mas sem os riscos para a saúde humana associados. Vários grupos propuseram que a luz Far-UVC (207 a $222 \mathrm{~nm}$ ), que pode ser gerada usando lâmpadas, é uma tecnologia antimicrobiana eficiente e segura que pode ser implantada em locais públicos ocupados ${ }^{26,45,47}$.

\section{Metodologia}

Essa pesquisa foi desenvolvida a partir de uma revisão sistemática, no qual foram realizadas buscas na literatura científica durante os meses de julho a novembro de 2020 . Para a elaboração desta revisão sistemática, utilizou-se, em primeiro momento, a definição do objetivo geral, a solução do problema apresentado na introdução é como base de estudo, os artigos encontrados na literatura. Sendo assim, foram realizadas buscas nas bases de dados ScienceDirect, Web of Science, pubMED, SciELO, Google Scholar e World Wide Science, escolhidas por apresentarem a ferramenta que destaca e filtra as publicações relevantes para o tema. Após a leitura do artigo de embasamento "Far-UVC light (222 nm) efficiently and safe lyinactivates airborne human coronaviruses" a fim de filtrar as principais palavras chave, assim facilitaria o processo de triagem para a escolha dos artigos, limitando a quantidade de trabalhos e concentrando naqueles mais relevantes para o tema.

Durante esse processo, foram utilizados os termos "uvc" AND "wave" AND "ultraviolet" AND "radiation" AND "light" AND "intensity" para a busca dos artigos relacionados a UCV e para a busca de artigos relacionados a ozônio foram utilizados "ozone" AND "air" AND "disinfection" AND "virus" AND "bacteria" AND "environment" AND "decontamination" AND "airdecontamination". Assim, foi definidas as strings de busca, na qual funcionasse corretamente com os operadores lógicos AND e OR, além de ser aplicável em todas as bases de busca. Tais strings se limitaram a apresentar termos como desinfecção (disinfection), radiação (radiation), 
ultravioleta C (UVC), ozônio (ozone) e descontaminação do ar (air-decontamination). Destacando que para a pesquisa filtraram -se somente os artigos científicos de língua inglesa por conta de a literatura brasileira ser limitada acerca do tema, além de limitar o período de busca em 4 anos visando coletar somente informações mais recentes.

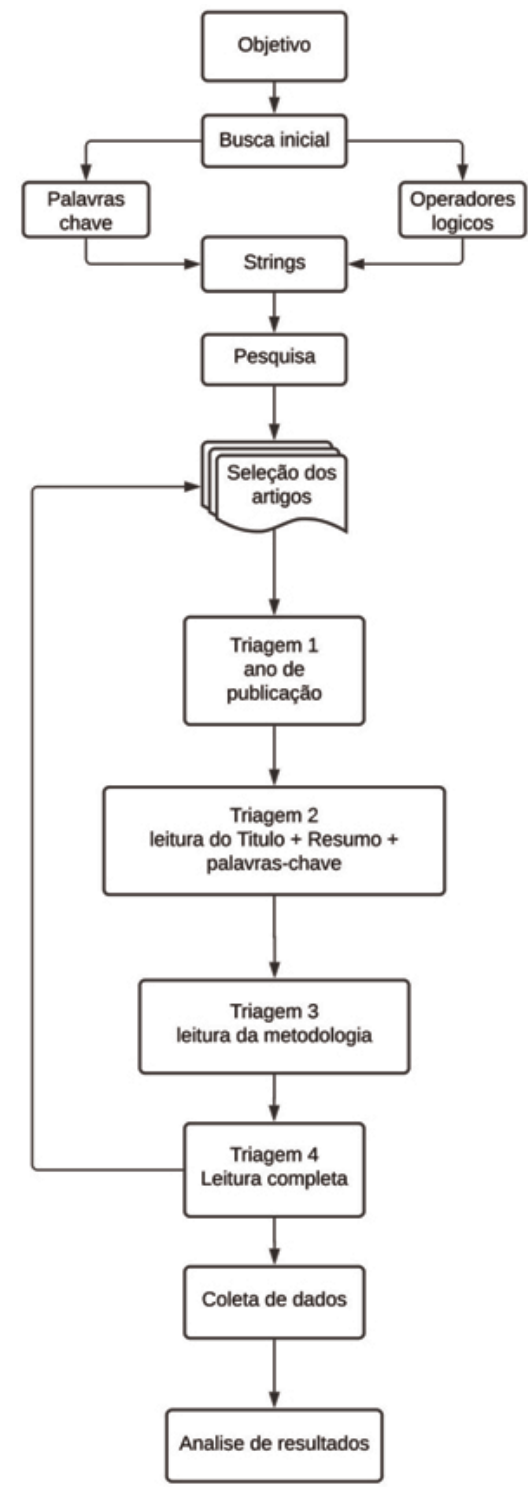

Figura 7: Fluxograma de seleção de artigos. Fonte: Autores
Como critério de inclusão buscou-se filtrar as publicações por 3 filtros distintos, conforme descrito no fluxograma da Figura 7. No primeiro filtro foi realizada a leitura parcial do artigo, sendo lido título, resumo e palavras-chave, com o propósito de identificar semelhanças entre o objetivo da revisão sistemática e o artigo lido.

No segundo, para os artigos que passaram no primeiro filtro foi feita a leitura da metodologia, tendo como objetivo escolher produções científicas que demonstram uma parte experimental mais elaborada. Por fim, no terceiro e último filtro, foi realizada a leitura completa dos artigos, com o propósito de coletar as informações chaves que se ligam ao objetivo proposto desta revisão. Para mais, durante esta etapa observaram-se os critérios de qualificação como a quantidade de citações, qualidade do periódico, ano de publicação, variabilidade de amostragem do experimento e H-Index da autoria. Para a aplicação de ambos os critérios se utilizou a ferramenta StArt, na qual facilita a separação dos artigos em cada fase.

\section{Resultados}

Por meio de busca preliminar na bibliografia, foram encontrados cerca de 205 artigos, conforme mostra a Figura 8, contemplando as bases de buscas utilizadas, conforme critérios de escolha expostos na metodologia.

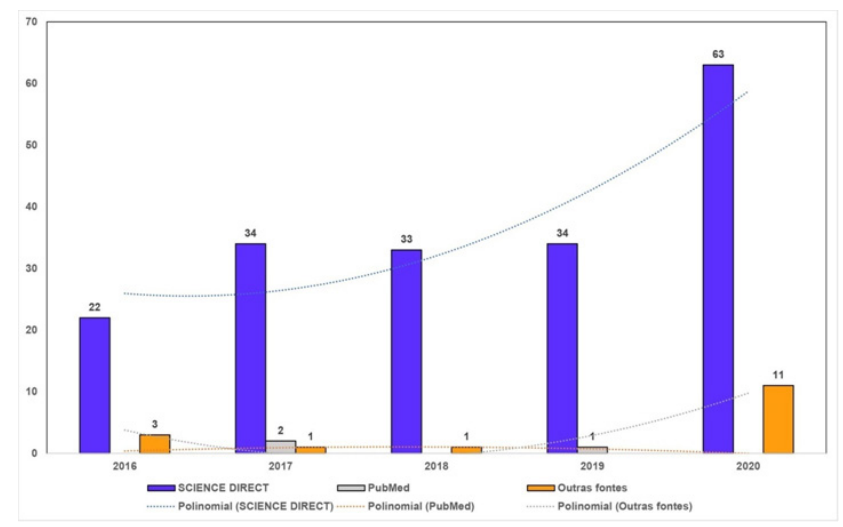

Figura 8: Publicações por plataformas. Fonte: Autores 
A curva de tendência de publicações aumentou nos últimos anos, visto que a preocupação com agentes patológicos é algo bastante atual. A disseminação desses agentes é feita rapidamente devido à globalização e à facilidade do acesso ao transporte por todas as classes. Aplicando os critérios descritos na metodologia, foi possível realizar uma filtragem dos 205 artigos para 44 catalogados na Tabela 1, contendo um extrato simplificado de cada publicação com título do trabalho, revista publicada, Qualis, número de citações, autor principal e ano de publicação. Nota-se os trabalhos que possuem grande relevância para o desenvolvimento dessa pesquisa foram publicados em revistas em sua grande maioria com Qualis A e algumas de peso, como Nature, contendo diversas citações, mostrando a tamanha relevância dos resultados publicados.

Dos artigos selecionados para leitura, foi feito um teorema de pareto demonstrando o interesse de cada país no assunto vigente, representado no gráfico da Figura 9.

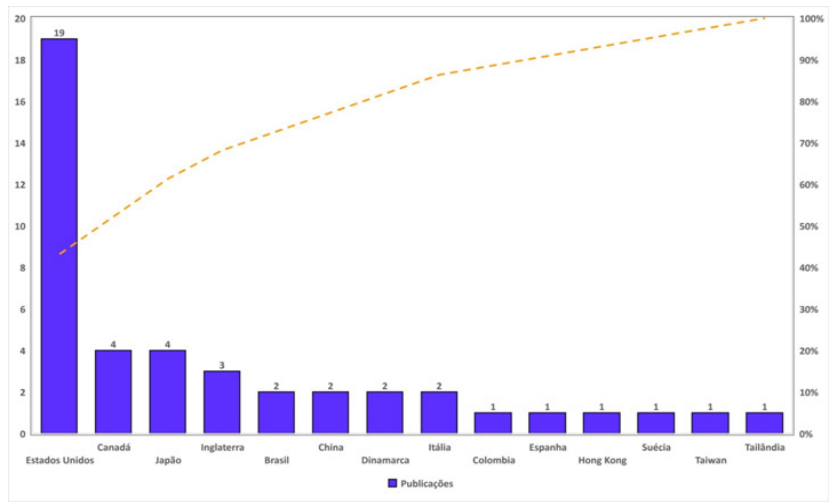

Figura 9: Publicações selecionadas por países. Fonte: Autores

Com a recente descoberta da Covid-19, uma variação do sars vírus que tem a capacidade de permanecer infeccioso em superfícies por longos períodos, indica ser um vírus resistente quando comparado com outros vírus envelopados (vírus que possuem externamente uma camada lipídica) ${ }^{13,48}$. Previsivelmente, desinfetantes como alvejantes, fenol e formaldeídos foram considerados eficazes na desativação do vírus; os detergentes, entretanto, foram menos eficientes ${ }^{10}$. $\mathrm{O}$ ozônio oferece a vantagem de por conta de ser um gás, sua capacidade de adentrar e desinfetar espaços de difícil acesso ${ }^{8,13,48}$. Além disso, o gás ozônio $O^{3}$ possui uma vida útil relativamente baixa revertendo-se para oxigênio após uma hora ${ }^{8}$.

No artigo Ozone Disinfection of SARS-Contaiminated Areas escrito pelos pesquisadores Kenneth K. K. LAM B.Sc. (Hons), M. Phil. ${ }^{8}$ com o propósito de testar a eficácia do ozônio $O^{3}$ na redução de formação de colônias de bactérias transportadas pelo ar, uma sala de $12 \mathrm{~m}^{2}$ de área foi escolhida para o teste ${ }^{8}$. Por conta do ozônio em altas quantidades ser prejudicial a sala foi evacuada antes do experimento. Para as dimensões da sala, foi utilizado um gerador de ozônio com vazão de saída de $2 \mathrm{~g} / \mathrm{h}$, este gerador tem a capacidade de manter altas concentrações de ozônio $(0,5-5 \mathrm{ppm})$ no interior da sala (Figura 10) ${ }^{8}$. Foi utilizado também um ventilador para garantir uma boa distribuição de ozônio. Após fechar todas as portas e janelas, o gerador foi ligado por um dispositivo remoto localizado do lado de fora para iniciar o processo de ozonização ${ }^{8}$. A concentração de ozônio foi monitorada através de um sensor digital. Foram testados 3 níveis diferentes de ozônio sendo eles $0,5,2,5$ e 5 ppm (ppm parte por milhão, $1 \mathrm{ppm}$ é igual $\left.1 \mathrm{~g} / \mathrm{m}^{3}\right)^{8}$. Após o desligamento do gerador, o nível de ozônio na sala começou a cair gradativamente a medida que estava se auto decompondo em oxigênio ${ }^{8}$. Por razões de segurança, só foi liberada a entrada de pessoas na sala quando o nível de ozônio no ambiente estava abaixo de 0,02 $\mathrm{ppm}^{8}$. Em geral, a concentração de ozônio demora cerca de 60 minutos para atingir concentrações seguras após o desligamento do gerador ${ }^{8}$.



Figura 10: Processo de ozonização ( 0.5 ppm por 30 minutos.). Fonte: Yang J-H, Wu U-I, Tai H-M, Sheng W-H. Effectiveness of an ultraviolet-C disinfection system for reduction of healthcareassociated pathogens. J Microbiol Immunol Infect. 2019;52(3):487493. doi:10.1016/j.jmii.2017.08.0178 
Tabela 1: Resultado dos artigos catalogados. Fonte: Autores

\begin{tabular}{|c|c|c|c|c|c|}
\hline TÍTULO & REVISTA & QUALIS & CITAÇÕES & AUTOR PRINCIPAL & ANO \\
\hline $\begin{array}{l}\text { Far-UVC light ( } 222 \mathrm{~nm}) \\
\text { efficiently and safely } \\
\text { inactivates airborne human } \\
\text { coronaviruses }\end{array}$ & Nature & A1 & 48 & Manuela Buonanno & 2020 \\
\hline $\begin{array}{l}\text { Improving Indoor Air Quality } \\
\text { through the Use of Ultraviolet } \\
\text { Technology in Commercial } \\
\text { Buildings }\end{array}$ & Sciencedirect & $\mathrm{A} 2$ & 8 & Danielde Robles P.E. & 2017 \\
\hline $\begin{array}{l}\text { Efficacy of manual cleaning } \\
\text { and an ultraviolet } \mathrm{C} \text { room } \\
\text { decontamination device in } \\
\text { reducing health care-associated } \\
\text { pathogens on hospital floors }\end{array}$ & $\begin{array}{l}\text { American Journal } \\
\text { of Infection Control }\end{array}$ & Al & 15 & AishatMustapha & 2018 \\
\hline $\begin{array}{l}\text { Investigation of ultrafast } \\
\text { optical nonlinearities in } \\
\text { novel bis-chalcone derivatives }\end{array}$ & $\begin{array}{l}\text { OPTICS AND LASER } \\
\text { TECHNOLOGY }\end{array}$ & A1 & 2 & YongYang & 2020 \\
\hline $\begin{array}{l}\text { Ozone Disinfection of } \\
\text { SARS-Contaiminated Areas }\end{array}$ & PLOS ONE & A1 & 17 & Marie-Eve Dubuis & 2020 \\
\hline $\begin{array}{l}\text { Ozone and oxidation therapies } \\
\text { as a solution to the emerging } \\
\text { crisis in infectious disease } \\
\text { management: A review of } \\
\text { current knowledge and experience }\end{array}$ & Medical GasResearch & $\mathrm{B} 2$ & 15 & Robert Jay Rowen & 2019 \\
\hline $\begin{array}{l}\text { Inactivation of severe acute } \\
\text { respiratory syndrome coronavirus } \\
2 \text { (SARS-CoV-2) by gaseous } \\
\text { ozone treatment }\end{array}$ & $\begin{array}{l}\text { Journalof Hospital } \\
\text { Infection }\end{array}$ & B2 & 0 & H. Yano & 2020 \\
\hline $\begin{array}{l}\text { On airborne transmission } \\
\text { and control of SARS-Cov-2 }\end{array}$ & $\begin{array}{l}\text { Science of The } \\
\text { Total Environment }\end{array}$ & A1 & 37 & Maosheng Yao & 2020 \\
\hline $\begin{array}{l}\text { Bactericidal Effects of High } \\
\text { Airborne Ozone Concentrations } \\
\text { on Escherichia coli and } \\
\text { Staphylococcus aureus }\end{array}$ & $\begin{array}{l}\text { Ozone: Science \& } \\
\text { Engineering }\end{array}$ & $\mathrm{A} 2$ & 107 & Wladyslaw J. Kowalski & 1997 \\
\hline $\begin{array}{l}\text { Potential Cytoprotective } \\
\text { Activity of Ozone Therapy }\end{array}$ & ANTIOXIDANTS & $\mathrm{B} 1$ & 32 & Gregorio Martínez-Sánchez & 2020 \\
\hline
\end{tabular}


Tabela 1: Resultado dos artigos catalogados. Fonte: Autores - continuação

\begin{tabular}{|c|c|c|c|c|c|}
\hline TÍTULO & REVISTA & QUALIS & CITAÇÕES & AUTOR PRINCIPAL & ANO \\
\hline $\begin{array}{l}\text { Ozone efficacy for the control } \\
\text { of airborne viruses: Bacteriophage } \\
\text { and norovirus models }\end{array}$ & PLOS ONE & A1 & 17 & Marie-Eve Dubuis & 2020 \\
\hline $\begin{array}{l}\text { A novel upper-room UVC-LED } \\
\text { irradiation system for disinfection } \\
\text { of indoor bioaerosols under } \\
\text { different operating and airflow } \\
\text { conditions }\end{array}$ & $\begin{array}{l}\text { Journal of Hazar } \\
\text { dous Materials }\end{array}$ & A1 & 1 & SundayS.Nunayon & 2020 \\
\hline $\begin{array}{l}\text { In-Room Ultraviolet Air } \\
\text { Filtration Units Reduce } \\
\text { Airborne Particles During } \\
\text { Total Joint Arthroplasty }\end{array}$ & $\begin{array}{l}\text { journal of } \\
\text { orthopaedicre } \\
\text { search }\end{array}$ & A2 & 1 & Hiba K Anis & 2020 \\
\hline $\begin{array}{l}\text { Exploratory clinical trial on } \\
\text { the safety and bactericidal effect } \\
\text { of } 222-\mathrm{nm} \text { ultraviolet C } \\
\text { irradiation in healthy humans }\end{array}$ & PLOS ONE & A1 & 3 & Tomoaki Fukui & 2020 \\
\hline $\begin{array}{l}\text { Disinfection of Pseudomonas } \\
\text { aeruginosa biofilm contaminated } \\
\text { tube lumens with ultraviolet } \mathrm{C} \\
\text { light emitting diodes }\end{array}$ & Biofouling & A1 & 42 & Jimmy Bak & 2010 \\
\hline $\begin{array}{l}\text { Impact of an ultraviolet } \\
\text { air sterilizer on cardiac } \\
\text { surgery patients, a randomized } \\
\text { clinical trial }\end{array}$ & medicina clinica & B2 & 2 & María Heredia-Rodríguez & 2018 \\
\hline $\begin{array}{l}\text { Enhanced terminal room } \\
\text { disinfection and acquisition } \\
\text { and infection caused by } \\
\text { multidrug-resistant organisms } \\
\text { and Clostridium difficile (the } \\
\text { Benefits of Enhanced Terminal } \\
\text { Room Disinfection study): } \\
\text { a cluster-randomised, } \\
\text { multicentre, crossover study }\end{array}$ & The Lancet & A1 & 187 & DJ Anderson & 2017 \\
\hline $\begin{array}{l}\text { 207-nm UV light - A promising } \\
\text { tool for safe low-cost reduction } \\
\text { of surgical site infections. } \\
\text { II: In-vivosafetystudies }\end{array}$ & PLOS ONE & A1 & 47 & M Buonanno & 2016 \\
\hline $\begin{array}{l}\text { Decontamination and reuse } \\
\text { of N95 filtering facemask } \\
\text { respirators: A systematic } \\
\text { review of the literature }\end{array}$ & $\begin{array}{l}\text { American Journal } \\
\text { of Infection Control }\end{array}$ & A1 & 16 & CE Rodriguez-Martinez & 2020 \\
\hline
\end{tabular}


Tabela 1: Resultado dos artigos catalogados. Fonte: Autores - continuação

\begin{tabular}{|c|c|c|c|c|c|}
\hline TÍTULO & REVISTA & QUALIS & CITAÇÕES & AUTOR PRINCIPAL & ANO \\
\hline $\begin{array}{l}\text { Shining a light on the } \\
\text { pathogenicity of health } \\
\text { care providers' mobile phones: } \\
\text { Use of a novel ultraviolet-C } \\
\text { wave disinfection device }\end{array}$ & $\begin{array}{l}\text { American Journal } \\
\text { of Infection Control }\end{array}$ & A1 & 3 & S Malhotra & 2020 \\
\hline $\begin{array}{l}\text { Can ultraviolet light C } \\
\text { decrease the environmental } \\
\text { burden of antimicrobial-resistant } \\
\text { and -sensitive bacteria on textiles? }\end{array}$ & veterinarydermatology & B1 & 4 & JJ Bentley & 2016 \\
\hline $\begin{array}{l}\text { Time Effectiveness of } \\
\text { Ultraviolet C Light (UVC) } \\
\text { Emitted by Light Emitting } \\
\text { Diodes (LEDs) in Reducing } \\
\text { Stethoscope Contamination }\end{array}$ & $\begin{array}{l}\text { INTERNATIONAL } \\
\text { JOURNAL OF } \\
\text { ENVIRONMENTAL } \\
\text { RESEARCH AND } \\
\text { PUBLIC HEALTH }\end{array}$ & A2 & 28 & Gabriele Messina & 2016 \\
\hline $\begin{array}{l}\text { Ultraviolet Light } \\
\text { Fights New Virus }\end{array}$ & Engineering & A1 & 2 & Dana Mackenzie & 2020 \\
\hline $\begin{array}{l}\text { Disposable masks: Disinfection } \\
\text { and sterilization for reuse, and } \\
\text { non-certified manufacturing, } \\
\text { in the face of shortages during } \\
\text { the COVID-19 pandemic }\end{array}$ & Safety Science & A1 & 39 & JC Rubio-Romero & 2020 \\
\hline $\begin{array}{l}\text { Ultra violet germicidalir radiation } \\
\text { of influenza-contaminated N95 } \\
\text { filteringfacepiecerespirators }\end{array}$ & $\begin{array}{l}\text { American Journal } \\
\text { of Infection Control }\end{array}$ & A1 & 158 & D Mills & 2018 \\
\hline $\begin{array}{l}\text { Applications of ultraviolet } \\
\text { germicidal irradiation } \\
\text { disinfection in health care } \\
\text { facilities: Effective adjunct, } \\
\text { but not stand-alone technology }\end{array}$ & $\begin{array}{l}\text { American Journal of } \\
\text { Infection Control }\end{array}$ & A1 & 135 & F Memarzadeh & 2010 \\
\hline $\begin{array}{l}\text { Effectiveness of an ultraviolet-C } \\
\text { disinfection system for reduction } \\
\text { of healthcare-associated pathogens }\end{array}$ & $\begin{array}{l}\text { Journal of Microbiology, } \\
\text { Immunology and } \\
\text { Infection }\end{array}$ & A2 & 23 & Jui-Hsuan Yang & 2019 \\
\hline $\begin{array}{l}\text { Far-UVC light: A new tool } \\
\text { to control the spread of } \\
\text { airborne-mediated microbial } \\
\text { diseases }\end{array}$ & Nature & A1 & 114 & D Welch & 2018 \\
\hline $\begin{array}{l}\text { Evaluation of a low-intensity } \\
\text { ultraviolet-C radiation device } \\
\text { for decontamination of computer } \\
\text { keyboards }\end{array}$ & $\begin{array}{l}\text { American Journal of } \\
\text { Infection Control }\end{array}$ & A1 & 8 & AA Shaikh & 2016 \\
\hline
\end{tabular}


Tabela 1: Resultado dos artigos catalogados. Fonte: Autores - continuação

\begin{tabular}{|c|c|c|c|c|c|}
\hline TÍTULO & REVISTA & QUALIS & CITAÇÕES & AUTOR PRINCIPAL & ANO \\
\hline $\begin{array}{l}\text { Microbiological evaluation of } \\
\text { UV disinfection effectiveness } \\
\text { in a specialist cystic fibrosis } \\
\text { clinic }\end{array}$ & $\begin{array}{l}\text { Journal of Cystic } \\
\text { Fibrosis }\end{array}$ & A2 & 1 & O Allen & 2019 \\
\hline $\begin{array}{l}\text { The uses and limitations of a } \\
\text { hand-held germicidal ultraviolet } \\
\text { wand for surface disinfection }\end{array}$ & $\begin{array}{l}\text { Journal of Occupational } \\
\text { and Environmental } \\
\text { Hygiene }\end{array}$ & - & 4 & G Byrns & 2017 \\
\hline $\begin{array}{l}\text { Effectiveness of ultraviolet-c } \\
\text { light and a high-level disinfection } \\
\text { cabinet for decontamination of } \\
\text { n95 respirators }\end{array}$ & $\begin{array}{l}\text { PATHOGENS AND } \\
\text { IMMUNITY }\end{array}$ & - & 37 & JL Cadnum & 2020 \\
\hline THE STRUCTURE OF DNA & $\begin{array}{l}\text { HARBOR SYMPOSIA } \\
\text { ON QUANTITATIVE } \\
\text { BIOLOGY }\end{array}$ & B1 & 2048 & JD Watson & 1953 \\
\hline $\begin{array}{l}\text { Further evidence that far-UVC } \\
\text { for disinfection is unlikely to } \\
\text { cause erythema or pre-mutagenic } \\
\text { DNA lesions in skin. }\end{array}$ & $\begin{array}{l}\text { PHOTODERMATOLOGY, } \\
\text { PHOTOIMMUNOLOGY \& } \\
\text { PHOTOMEDICINE }\end{array}$ & B1 & 6 & Isla Rose Mary Barnard & 2020 \\
\hline $\begin{array}{l}\text { Ultraviolet-C decontamination } \\
\text { of a hospital room: Amount of } \\
\text { UV light needed }\end{array}$ & Burns & A2 & 18 & Marie Lindblad & 2020 \\
\hline $\begin{array}{l}\text { Far-UVC light }(222 \mathrm{~nm}) \\
\text { efficiently and safely } \\
\text { inactivates airborne human } \\
\text { coronaviruses }\end{array}$ & Nature & A1 & 48 & Manuela Buonanno & 2020 \\
\hline $\begin{array}{l}\text { Norovirus recovery from } \\
\text { floors and air after various } \\
\text { decontamination protocols }\end{array}$ & $\begin{array}{l}\text { Journal of Hospital } \\
\text { Infection }\end{array}$ & B2 & 4 & C L Ciofi-Silva & 2019 \\
\hline $\begin{array}{l}\text { Clinical, operational, and } \\
\text { financial impact of an } \\
\text { ultraviolet-C terminal } \\
\text { disinfection intervention } \\
\text { at a community hospital }\end{array}$ & $\begin{array}{l}\text { American Journal of } \\
\text { Infection Control }\end{array}$ & A1 & 10 & Robert Raggi & 2018 \\
\hline $\begin{array}{l}\text { Ultraviolet C light with } \\
\text { wavelength of } 222 \mathrm{~nm} \\
\text { inactivates a wide spectrum } \\
\text { of microbial pathogens }\end{array}$ & $\begin{array}{l}\text { Journal of Hospital } \\
\text { Infection }\end{array}$ & B2 & 7 & Kouji Narita & 2020 \\
\hline
\end{tabular}


Tabela 1: Resultado dos artigos catalogados. Fonte: Autores - continuação

\begin{tabular}{|c|c|c|c|c|c|}
\hline TÍTULO & REVISTA & QUALIS & CITAÇÕES & AUTOR PRINCIPAL & ANO \\
\hline $\begin{array}{l}\text { Long-term Effects of 222-nm } \\
\text { ultraviolet radiation C Sterilizing } \\
\text { Lamps on Mice Susceptible to } \\
\text { Ultraviolet Radiation }\end{array}$ & $\begin{array}{l}\text { Photochemistry and } \\
\text { Photobiology }\end{array}$ & A1 & 12 & NozomiYamano & 2020 \\
\hline $\begin{array}{l}\text { Efficacy of an automated } \\
\text { ultraviolet } \mathrm{C} \text { device in a } \\
\text { shared hospital bathroom }\end{array}$ & $\begin{array}{l}\text { American Journal of } \\
\text { Infection Control }\end{array}$ & A1 & 10 & Jesse Cooper & 2016 \\
\hline $\begin{array}{l}\text { Viability evaluation of layered } \\
\text { cell sheets after ultraviolet light } \\
\text { irradiation of } 222 \mathrm{~nm}\end{array}$ & Regenerative Therapy & & 0 & Nami Hanamura & 2020 \\
\hline $\begin{array}{l}\text { Comparative effectiveness } \\
\text { of rapid-cycle ultraviolet } \\
\text { decontamination to chemical } \\
\text { decontamination on high-touch } \\
\text { communication devices }\end{array}$ & $\begin{array}{l}\text { American Journal of } \\
\text { Infection Control }\end{array}$ & A1 & 1 & Marisol Resendiz & 2019 \\
\hline $\begin{array}{l}\text { Bioactive Lipids in } \\
\text { COVID-19-Further Evidence }\end{array}$ & $\begin{array}{l}\text { Archivesof Medical } \\
\text { Research }\end{array}$ & A2 & 2 & Einstein, A., B. Podolsky & 2020 \\
\hline $\begin{array}{l}\text { Characterization of Ozone } \\
\text { Disinfection of Murine } \\
\text { Norovirus }\end{array}$ & ASM & A2 & 67 & MY Lim & 2010 \\
\hline
\end{tabular}

A quantidade de bactérias transportadas pelo ar na sala foi medida antes e após cada processo de ozonização, essa medição foi realizada utilizando um exibidor de estágio único Andersen N-6 com Agar em uma placa de petri ${ }^{4}$. Para cada amostragem, foram coletados 283 litros de $\operatorname{ar}^{8}$. A placa de petri foi incubada a $35^{\circ} \mathrm{C}$ por 48 horas antes da contagem8. A eficiência da desinfecção através do ozônio em diferentes concentrações pode ser observada na Tabela $2^{8}$.

Tabela $2^{8}$ : Redução de bactérias transportadas pelo ar após ozonização. Fonte: Autores

\begin{tabular}{llll}
\hline Concentração de ozônio $(0,5 \mathrm{ppm})$ & 0,5 & 2,5 & 5 \\
\hline Antes da ozonização $\left(\mathrm{CFU} / \mathrm{m}^{3}\right)$ & 592 & 612 & 552 \\
Depois da ozonização $\left(\mathrm{CFU} / \mathrm{m}^{3}\right)$ & 169 & 42 & 57 \\
Redução (\%) & 71,5 & 93,1 & 89,6
\end{tabular}

Os resultados mostram que o ozônio é eficaz na redução de bactérias transportadas pelo ar $^{8}$. No nível de ozônio mais alto, o efeito de esterilização aumentou mais de $90 \%$ do ar, assim as bactérias podem ser reduzidas na concentração de $2,5 \mathrm{ppm}^{4}$. O aumento de concentração de ozônio para 5 ppm não foi benéfico na redução de bactérias $^{8}$. No artigo Bactericidal Effects of High Airborne Ozone Concentrationson Escherichia coli and Staphylococcus aureus escrito pelos pesquisadores WJ Kowalski,WPBahnfleth ETS Whittam que realizaram um experimento semelhante expondo placas de petri com Escherichia coli e Staphylococcus aureus a concentrações altas de ozônio, neste segundo experimento, foi alcançada uma taxa de mortandade superiores a $99,99 \%$ para ambas as espécies ${ }^{12}$. A diminuição da taxa de mortalidade do primeiro experimento se dá pelo fato de que a sala 
testada não estava $100 \%$ vedada, pois a porta era aberta brevemente após cada amostragem de ar para a troca das placas de petri ou seja era inevitável a troca de $\operatorname{ar}^{12}$. Embora a temperatura e o ph do ozônio sejam um fator crucial na eficácia do ozônio como agente germicida o artigo Characterization of Ozone Disinfection of Murine Norovirus afirma que, tanto a $20^{\circ} \mathrm{C}$ quanto a $5^{\circ} \mathrm{C}$, o a taxa de inativação foi maior em $\mathrm{pH} 5,6$ do que em $\mathrm{pH}$ 7 , isso diferença foi significativa com base no modelo EFH (P 0,05 pelo teste F)49. O MNV foi inativado pelo ozônio mais rapidamente em temperaturas mais baixas do que em temperaturas mais altas, mas a diferença não foi significativa ${ }^{49}$.

Em contrapartida, os pesquisadores $\mathrm{H}$. Yano $\mathrm{R}$. Nakano Y. Suzuki A. Nakano K. Kasahara H. Hosoi que realizaram um experimento semelhante aos citados, porém utilizando uma cepa de SARS-CoV-2, que foi isolada e fornecida pelo National Institute of Infectious Diseases, Japan ${ }^{10}$. As culturas de vírus foram colhidas por dois ciclos de congelamento e descongelamento e clarificadas por centrifugação de $10.000 \mathrm{~g}$ por $15 \mathrm{~min}$ a $4{ }^{\circ} \mathrm{C}^{22}$. Sendo submetido o sobrenadante à ultrafiltração, as placas foram deixadas secar antes da exposição ao gás ozônio e expostas ao ozônio imediatamente após a secagem. As placas foram colocadas em uma caixa de acrílico hermética à prova de ozônio (altura: $23 \mathrm{~cm}$, profundidade: $30 \mathrm{~cm}$, largura: $40 \mathrm{~cm}$ ) com o dispositivo gerador de gás ozônio (TM-04OZ; Tamura TECO Ltd., Japão) e tinham $15 \mathrm{~cm}$ longe do dispositivo ${ }^{10}$. As placas foram então expostas a uma concentração de 1,0 ppm de ozônio por 60 minutos (concentração-tempo e 6,0 ppm de ozônio a $55 \mathrm{~min}$, à temperatura de $25^{\circ} \mathrm{C}$ e umidade relativa de $60-80 \% 30$. Em cada experimento, placas colocadas por 60 ou 55 minutos sem exposição ao ozônio foram usadas como controle. Este estudo foi conduzido em um laboratório BSL-3 na Nara Medical University ${ }^{10}$. O ensaio de placa antes da exposição ao ozônio foi de 1,7 $\times 107 \mathrm{pfu} / \mathrm{mL}$. O título após a exposição de 1,0 ppm de ozônio em 60 min foi 1,7 × 104 em comparação com 5,8 $\times 105 \mathrm{pfu} / \mathrm{mL}$ para o controle10. Após a exposição a 6,0 ppm de ozônio em 55 min, o título foi menor ou igual a
$1,0 \times 103 \mathrm{pfu} / \mathrm{mL}$, em comparação com 2,0 × $106 \mathrm{pfu} /$ $\mathrm{mL}$ para o controle ${ }^{10}$. O título diminuiu significativamente após a exposição ao ozônio, sugerindo que o ozônio inativou o SARS-CoV-210.

Revisando a bibliografia, assim como o ozônio o uso do espectro $\mathrm{C}$ do ultravioleta, elimina agentes patogênicos, pois passa através da parede celular destruindo o material genético do mesmo, no qual a onda $222-n m$, contém características germicidas sem provocar problemas de saúde aos humanos expostos, porém apresenta um problema de dimensionamento em que a exposição para determinados sistemas é diferente, para sítios com humanos, a exposição recomendada é cerca de $500[\mathrm{~mJ} /$ $\mathrm{cm}^{2}$ ], demandando mais tempo para maior eficácia do sistema ${ }^{4,17,44,45}$.

Segundo o artigo por Fukui, T. et al.Exploratory clinical trial on the safety and bactericida lef fect of $222-n m$ ultraviolet $\mathrm{C}$ irradiation in healthy humans, um experimento foi desenvolvido com 20 voluntários saudáveis com objetivo de testar a exposição ao UVC17. O dorso dos voluntariados foi irradiado com UVC $222-\mathrm{nm}$ a $50-500\left[\mathrm{~mJ} / \mathrm{cm}^{2}\right]$ e o eritema induzido (vermelhidão da pele) foi avaliado. Posteriormente, o dorso dos voluntários foram irradiados com quantidade máxima de UVC não causando eritema, e os swabs de pele antes e após a irradiação foram cultivados ${ }^{17}$. O número de colônias formadas após 24 horas foi medido, além disso, o dímero de ciclobuteno pirimidina (CPD) como um indicador de dano ao DNA foi medido usando tecidos da pele das regiões não irradiadas e irradiadas ${ }^{17}$. Todos os indivíduos não apresentaram eritema em todas as doses. As costas dos voluntários foram irradiadas a500 $\left[\mathrm{mJ} / \mathrm{cm}^{2}\right]$, e o número de colônias bacterianas encontrados nos swabs foi significativamente diminuído pela irradiação UVC de $222-n m$ como pode ser visto na Figura $11^{17}$. A quantidade de CPD produzida na região irradiada foi ligeiramente, mas significativamente maior do que na região não irradiada ${ }^{17}$. 


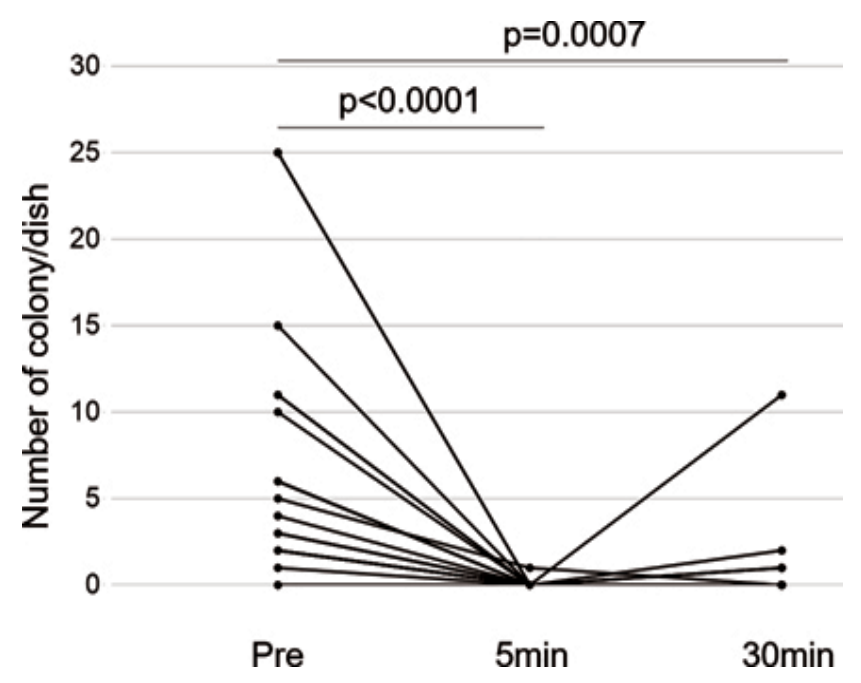

Figura 11: Número de colônias bacterianas em suspensão no swab. Fonte: Exploratory clinical trial on the safety and bactericidal effect of 222-nm ultraviolet $\mathrm{C}$ irradiation in healthy humans ${ }^{17}$.

$\mathrm{Na}$ Figura 12, é demonstrado o processo experimental realizado pelos pesquisadores Manuela Buonanno, David Welch, Igor Shuryak\& David J. Brenner publicados na revista Nature, no qual foram irradiados por FAR UVC células pulmonares infectadas a partir de alfa e beta $\mathrm{HCOV}^{4}$. A fluorescência verde indica qualitativamente as células infectadas e em azul DAPI é um marcador fluorescente que se liga fortemente a regiões de DNA ricas em adenina-timina ${ }^{4}$. Os resultados do experimento sugerem que ambas as cepas de coronavírus estudadas têm alta sensibilidade semelhante a UVC distante ativação ${ }^{4}$. A regressão linear robusta produziu intervalos de confiança de 95\% sobrepostos para a taxa de inativação coronavírus têm tamanhos genômicos semelhantes, o que é um determinante primário da sensibilidade UVC, é razoável esperar que a luz UVC distante mostre uma eficiência de inativação semelhante contra todos os coronavírus humanos, incluindo SARS-CoV-2. Os dados obtidos neste experimento são consistentes com esta hipótese ${ }^{4}$.
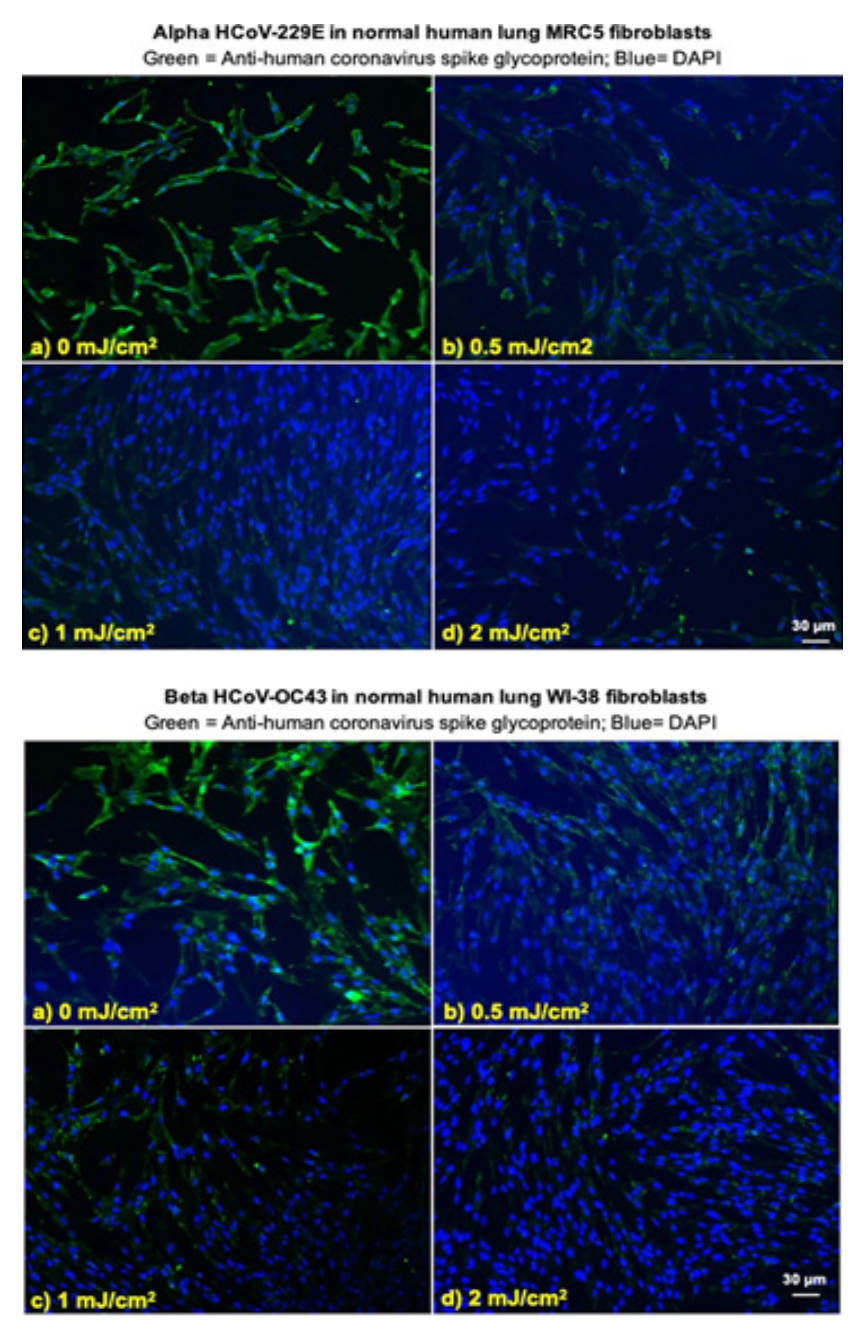

Figura 12: Ação da radiação UVC $(222 \mathrm{~nm})$ em secreção pulmonar infectada com alfa e beta HCoV. Fonte: Far-UVC light ( $222 \mathrm{~nm})$ efficiently and safely inactivates airborne human coronaviruses ${ }^{4}$

O mesmo experimento foi feito com ratos por outro grupo de pesquisadores, em que as cobaias foram expostas a diversas ao comprimento de onda de $222 \mathrm{~nm}, 254 \mathrm{~nm}$ e BB-UVB44. Na Figura 13, é possível identificar que o espectro de 222 não causou nenhuma resposta inflamatória na pele quanto nos olhos, diferente do comprimento de onda BB-UVB (305 - $325 \mathrm{~nm})$ que é notória a formação de inflamação na retina e na derme da cobaia ${ }^{44}$. 




Figura 13: Resultados da córnea e epiderme das cobaias para cada irradiador. Fonte: Long-term Effects of 222-nm ultraviolet radiation C Sterilizing Lamps on Mice Susceptible to Ultraviolet Radiation44.

A utilização conjunta ou separada de ambos os métodos apresentados se faz bastante necessária visto a atual necessidade de desinfecção de áreas públicas. Já sendo realizada a pesquisa com testes experimentais por meio da utilização das duas tecnologias aplicadas em uma plataforma totalmente móvel e autônoma com sistema integrado de luz $\mathrm{UVC}+\mathrm{O}_{3}$, ventilação e ultrafiltração, o que permite a coleta de dados e tornando viável a aprimoração desses meios de desinfecção aplicados em conjunto conforme Figura 14.

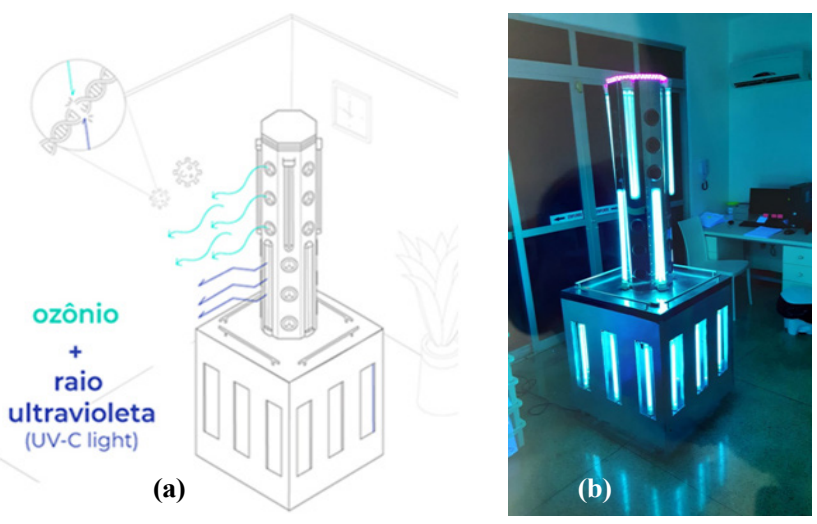

Figura 14: (a) Proposta inicial do Duo Cannon com esboço do protótipo. (b) Teste preliminares com protótipo. Fonte: Autores.
A Tecnologia proposta foi denominada Duo Cannon, que atua como dois canhões contra os minúsculos patógenos em suspensão no ar e em superfícies, faz uso do canhão (1) UVC e canhão (2) Ozônio. Esta solução foi desenvolvida pensando em um primeiro momento nos agentes de saúde, que são os mais suscetíveis a serem infectados nos hospitais. Depois ampliando a sua aplicação para os mais variados ambientes, como em áreas de convívio público, transportes públicos, ambulâncias, indústrias em geral, farmácias, bancos, Instituto Médico Legal, escolas, academias, entre outros, mostrando grandes perspectivas futuras para o avanço dos testes experimentais e aplicações.

\section{Conclusão}

Essa descoberta abre um leque de oportunidades para futuros projetos de salas limpas, salas de cirurgias, sistemas de ar-condicionado e praticamente todos os sistemas de fluido nos quais possa haver agentes patológicos. De modo que a irradiação UVC de $222 \mathrm{~nm}$ e insuflação de ozônio demonstraram aplicações relevantes no tratamento de infecções de sítio cirúrgico e no controle de patógenos transmitidos pelo ar e por alimentos. Ambos os meios de mitigação quando comparados com outros elementos já utilizados tem a vantagem de não deixar resíduos tornando a área segura após a utilização. $O$ gás ozônio pode atingir todos os cantos do ambiente, incluindo locais que podem ser difíceis de obter com líquidos convencionais e procedimentos de limpeza manual. Além disso, o gás ozônio é muito fácil de fabricar, pois é produzido por eletrólise e não requer reposição de matéria-prima.

\section{Referências}

1. Huang, C. et al.Clinical features of patients infected with 2019 novel coronavirus in Wuhan, China. Lancet395, 497-506 2020.

2. Ma, J. Coronavirus: China's first confirmed Covid-19 case traced back to November 17. https://www.scmp.com/news/china/society/ article/3074991/coronavirus-chinas-first-confirmed-covid-19-casetraced-back.

3. OMS. WHO Coronavirus Disease (COVID-19) Dashboard. https:// covid19.who.int/. 
4. Buonanno, M., Welch, D., Shuryak, I. \& Brenner, D. J. Far-UVC light $(222 \mathrm{~nm})$ efficiently and safely inactivates airborne human coronaviruses. Sci. Rep.10, 102852020.

5. de Robles, D. \& Kramer, S. W. Improving Indoor Air Quality through the Use of Ultraviolet Technology in Commercial Buildings. Procedia Eng.196, 888-894 2017.

6. Mustapha, A., Alhmidi, H., Cadnum, J. L., Jencson, A. L. \& Donskey, C. J. Efficacy of manual cleaning and an ultraviolet $\mathrm{C}$ room decontamination device in reducing health care-associated pathogens on hospital floors. Am. J. Infect. Control46, 584-586 2018.

7. Yang, Y. et al. Investigation of ultrafast optical nonlinearities in novel bis-chalcone derivatives. Opt. Laser Technol.123, 1059032020.

8. LAM, K. K. K. Ozone Disinfection of SARS-Contaiminated Areas. 2860, 1-6 2003.

9. Rowen, R. J. Ozone and oxidation therapies as a solution to the emerging crisis in infectious disease management: A review of current knowledge and experience. Med. Gas Res.9, 232-237 2019.

10. Yano, H. et al. Inactivation of severe acute respiratory syndrome coronavirus 2 (SARS-CoV-2) by gaseous ozone treatment. J. Hosp. Infect.106, 837-838 2020.

11. Yao, M., Zhang, L., Ma, J. \& Zhou, L. On airborne transmission and control of SARS-Cov-2. Sci. Total Environ.731, 1391782020.

12. Kowalski, W. J., Bahnfleth, W. P. \& Whittam, T. S. Bactericidal Effects of High Airborne Ozone Concentrations on Escherichia coli and Staphylococcus aureus. Ozone Sci. Eng.20, 205-221 1998.

13. Martínez-Sánchez, G., Schwartz, A. \& Di Donna, V. Potential Cytoprotective Activity of Ozone Therapy in SARS-CoV-2/ COVID-19. Antioxidants9, 3892020.

14. Dubuis, M.-E. et al. Ozone efficacy for the control of airborne viruses: Bacteriophage and norovirus models. PLoS One 15, e0231164 (2020).

15. Nunayon, S. S., Zhang, H. H. \& Lai, A. C. K. A novel upper-room UVC-LED irradiation system for disinfection of indoor bioaerosols under different operating and airflow conditions. J. Hazard. Mater.396, 1227152020 .

16. Anis, H. K. et al. In-Room Ultraviolet Air Filtration Units Reduce Airborne Particles During Total Joint Arthroplasty. J. Orthop. Res.38, 431-437 2020.

17. Fukui, T. et al. Exploratory clinical trial on the safety and bactericidal effect of 222-nm ultraviolet $\mathrm{C}$ irradiation in healthy humans. PLoS One15, 1-13 2020.

18. Bak, J., Ladefoged, S. D., Tvede, M., Begovic, T. \& Gregersen, A. Disinfection of Pseudomonas aeruginosa biofilm contaminated tube lumens with ultraviolet $\mathrm{C}$ light emitting diodes. Biofouling 26, 31-38 2010.
19. Heredia-Rodríguez, M. et al. Impact of an ultraviolet air sterilizer on cardiac surgery patients, a randomized clinical trial. Med. Clin. (Barc).151, 299-307 2018.

20. Anderson, D. J. et al. Enhanced terminal room disinfection and acquisition and infection caused by multidrug-resistant organisms and Clostridium difficile (the Benefits of Enhanced Terminal Room Disinfection study): a cluster-randomised, multicentre, crossover study. Lancet389, 805-814 2017.

21. Akari. O mais seguro e moderno sistema de descontaminação de água e ar: a Luz Ultravioleta C. https://www.akarilampadas.com.br/ aplicacoes/introducao-a-luz-ultravioleta-uvc.php.

22. Buonanno, M. et al. 207-nm UV light - A promising tool for safe lowcost reduction of surgical site infections. II: In-vivo safety studies. PLoS One11, 1-12 2016.

23. Rodriguez-Martinez, C. E., Sossa-Briceño, M. P. \& Cortés, J. A. Decontamination and reuse of $\mathrm{N} 95$ filtering facemask respirators: A systematic review of the literature. Am. J. Infect. Control48, 152015322020.

24. Malhotra, S. et al. Shining a light on the pathogenicity of health care providers' mobile phones: Use of a novel ultraviolet-C wave disinfection device. Am. J. Infect. Control48, 1370-1374 2020.

25. Bentley, J. J., Santoro, D., Gram, D. W., Dujowich, M. \& Marsella, R. Can ultraviolet light $\mathrm{C}$ decrease the environmental burden of antimicrobial-resistant and -sensitive bacteria on textiles? Vet. Dermatol.27, 457-e121 2016.

26. Messina, G. et al. Time Effectiveness of Ultraviolet C Light (UVC) Emitted by Light Emitting Diodes (LEDs) in Reducing Stethoscope Contamination. Int. J. Environ. Res. Public Health13, 940 (2016).

27. Mackenzie, D. Ultraviolet Light Fights New Virus. Engineering6, 851-8532020.

28. Rubio-Romero, J. C., Pardo-Ferreira, M. del C., Torrecilla-García, J. A. \& Calero-Castro, S. Disposable masks: Disinfection and sterilization for reuse, and non-certified manufacturing, in the face of shortages during the COVID-19 pandemic. Saf. Sci.129, 104830 2020.

29. Mills, D., Harnish, D. A., Lawrence, C., Sandoval-Powers, M. \& Heimbuch, B. K. Ultraviolet germicidal irradiation of influenzacontaminated N95 filtering facepiece respirators. Am. J. Infect. Control46, e49-e55 2018.

30. Memarzadeh, F., Olmsted, R. N. \& Bartley, J. M. Applications of ultraviolet germicidal irradiation disinfection in health care facilities: Effective adjunct, but not stand-alone technology. Am. J. Infect. Control38, S13-S24 2010.

31. Yang, J.-H., Wu, U.-I., Tai, H.-M. \& Sheng, W.-H. Effectiveness of an ultraviolet-C disinfection system for reduction of healthcare-associated pathogens. J. Microbiol. Immunol. Infect.52, 487-493 2019. 
32. Welch, D. et al. Far-UVC light: A new tool to control the spread of airborne-mediated microbial diseases. Sci. Rep.8, 27522018.

33. Shaikh, A. A. et al. Evaluation of a low-intensity ultraviolet-C radiation device for decontamination of computer keyboards. Am. J. Infect. Control44, 705-707 2016.

34. Allen, O. et al. Microbiological evaluation of UV disinfection effectiveness in a specialist cystic fibrosis clinic. J. Cyst. Fibros.18, e37-e39 2019.

35. Byrns, G. et al. The uses and limitations of a hand-held germicidal ultraviolet wand for surface disinfection. J. Occup. Environ. Hyg.14, 749-757 (2017).

36. Cadnum, J. L. et al. Effectiveness of ultraviolet-c light and a highlevel disinfection cabinet for decontamination of $\mathrm{n} 95$ respirators. Pathog. Immun.5, 52-67 2020.

37. Watson, J. D. \& Crick, F. H. C. THE STRUCTURE OF DNA. Cold Spring Harb. Symp. Quant. Biol.18, 123-131 1953.

38. Barnard, I. R. M., Eadie, E. \& Wood, K. Further evidence that farUVC for disinfection is unlikely to cause erythema or pre-mutagenic DNA lesions in skin. Photodermatol. Photoimmunol. Photomed.36, 476-477 2020.

39. Lindblad, M., Tano, E., Lindahl, C. \& Huss, F. Ultraviolet-C decontamination of a hospital room: Amount of UV light needed. Burns46, 842-849 2020.

40. Buonanno, M., Welch, D., Shuryak, I. \& Brenner, D. J. Far-UVC light $(222 \mathrm{~nm})$ efficiently and safely inactivates airborne human coronaviruses. Sci. Rep.10, 1-8 2020.

41. Ciofi-Silva, C. L. et al. Norovirus recovery from floors and air after various decontamination protocols. J. Hosp. Infect.103, 328-334 2019.

42. Raggi, R., Archulet, K., Haag, C. W. \& Tang, W. Clinical, operational, and financial impact of an ultraviolet-C terminal disinfection intervention at a community hospital. Am. J. Infect. Control46, 122412292018 .

43. Narita, K. et al. Ultraviolet C light with wavelength of $222 \mathrm{~nm}$ inactivates a wide spectrum of microbial pathogens. J. Hosp. Infect.105, 459-467 2020.

44. Yamano, N. et al. Long-term Effects of 222-nm ultraviolet radiation C Sterilizing Lamps on Mice Susceptible to Ultraviolet Radiation. Photochem. Photobiol.96, 853-862 2020.

45. Cooper, J., Bryce, E., Astrakianakis, G., Stefanovic, A. \& Bartlett, $\mathrm{K}$. Efficacy of an automated ultraviolet $\mathrm{C}$ device in a shared hospital bathroom. Am. J. Infect. Control44, 1692-1694 2016.

46. Hanamura, N., Ohashi, H., Morimoto, Y., Igarashi, T. \& Tabata, Y. Viability evaluation of layered cell sheets after ultraviolet light irradiation of $222 \mathrm{~nm}$. Regen. Ther.14, 344-351 2020.
47. Resendiz, M., Horseman, T. S., Lustik, M. B., Nahid, A. \& West, G. F. Comparative effectiveness of rapid-cycle ultraviolet decontamination to chemical decontamination on high-touch communication devices. Am. J. Infect. Control47, 1135-1139 2019.

48. Das, U. N. Bioactive Lipids in COVID-19-Further Evidence. Arch. Med. Res. 2020 doi:10.1016/j.arcmed.2020.09.006.

49. Lim, M. Y., Kim, J.-M., Lee, J. E. \& Ko, G. Characterization of Ozone Disinfection of Murine Norovirus. Appl. Environ. Microbiol.76, 1120-1124 2010.

\section{Guilherme V. L. Silva*, Gustavo M. Camargo, José A. S. Neto, Igor D. Borges, Cláudio F. Oliveira \& Rosemberg R. F. Nunes}

Centro Universitário de Anápolis - UniEVANGÉLICA. Avenida Universitária, km 3,5, Centro Universitário, Anápolis, Goiás, Brasil.

*E-mail: vcguilherme@hotmail.com 